\title{
Patient-rated health status predicts prognosis following percutaneous coronary intervention with drug-eluting stenting
}

\author{
Susanne S. Pedersen • Henneke Versteeg • \\ Johan Denollet $\cdot$ Jin M. Cheng $\cdot$ Patrick W. Serruys • \\ Ron T. van Domburg
}

Accepted: 10 October 2010/Published online: 27 October 2010

(C) The Author(s) 2010. This article is published with open access at Springerlink.com

\begin{abstract}
Purpose In patients treated with percutaneous coronary intervention (PCI) with the paclitaxel-eluting stent, we examined whether patient-rated health status predicts adverse clinical events.

Methods Consecutive PCI patients treated with drug-eluting stenting $(N=870 ; 72.2 \%$ men; mean age $=62.6 \pm 11.5)$ completed the EQ-5D post-PCI. The EQ-5D levels were dichotomized into 'no problems' (level 1) versus 'problems' (levels 2,3); the visual analogue scale (VAS) was dichotomized using the 25 th percentile (cut-off $\leq 60$ ) indicating poor health status. Patients were followed up for 1-year clinical events (death or non-fatal myocardial infarction (MI)).

Results There were 53 deaths/MIs at follow-up. The EQ5D health status dimensions mobility (HR:2.23; 95\% CI:1.25-3.97), self-care (HR:3.09; 95\% CI:1.54-6.20), and self-reported health status as measured with the EQ-VAS (HR:2.94; 95\% CI:1.65-5.25) were independent predictors of death/MI and added to the predictive value of a model comprised of demographic and clinical characteristics. The EQ-5D dimensions usual activities, pain/discomfort, and anxiety/depression were not associated with adverse clinical events in adjusted analysis.
\end{abstract}

S. S. Pedersen $(\bowtie) \cdot$ H. Versteeg $\cdot$ J. Denollet Department of Medical Psychology, CoRPS-Center of Research on Psychology in Somatic diseases, Tilburg University, Room P506, PO Box 90153, 5000 Tilburg, LE, The Netherlands e-mail: s.s.pedersen@uvt.nl

URL: http://www.tilburguniversity.nl/corps/

S. S. Pedersen - J. M. Cheng · P. W. Serruys ·

R. T. van Domburg

Department of Cardiology, Thoraxcenter, Erasmus Medical

Center Rotterdam, Rotterdam, The Netherlands
Conclusions Patient-rated health status predicted adverse clinical events at 1-year follow-up in PCI patients treated with drug-eluting stenting, with the risk being more than 2 fold independent of disease severity and other demographic and clinical characteristics. It may be timely to adopt standard assessment of health status in clinical practice.

Keywords Health status - Mortality - Paclitaxel-eluting stent $\cdot$ Percutaneous coronary intervention

$\begin{array}{ll}\begin{array}{l}\text { Abbreviations } \\ \text { CABG }\end{array} & \begin{array}{l}\text { Coronary artery bypass graft surgery } \\ \text { Coronary artery disease }\end{array} \\ \text { CAD } & \text { Canadian Cardiovascular Society } \\ \text { COURAGE } & \begin{array}{l}\text { Clinical outcomes utilizing } \\ \text { revascularization and aggressive drug } \\ \text { evaluation trial }\end{array} \\ \text { MI } & \begin{array}{l}\text { Myocardial infarction } \\ \text { NYHA Class }\end{array} \\ & \begin{array}{l}\text { New York Heart Association functional } \\ \text { class (I-IV) }\end{array} \\ \text { PCI } & \text { Percutaneous coronary intervention } \\ \text { VAS } & \text { Visual analogue scale }\end{array}$

\section{Introduction}

Health status, as reported by the patient, is gaining increasing recognition as an important outcome measure in cardiovascular disease that may help bridge the gap between research and clinical practice [1]. Health status may be used to optimize the quality of care and may also aid in clinical decision-making and risk stratification, thereby enabling treatment recommendations to be tailored to individual patients [1-3]. 
Patient-rated health status refers to the impact of disease on patient symptoms, functional status and quality of life $[1,2]$. Alternative measures to health status exist, such as New York Heart Association (NYHA) functional class to assess the severity of heart failure and the Canadian Cardiovascular Society (CCS) classification to determine the severity of angina pectoris, but they have been criticized for their poor reproducibility and sensitivity to tap treatment-related changes [4, 5]. Moreover, the NYHA and CCS systems represent physician-rated measures, with studies showing a discrepancy between physician-rated and patient-rated health status, but also that physicians tend to underestimate functional disabilities in patients $[6,7]$.

Patient-rated health status has also been shown to predict mortality and morbidity in patients with coronary artery disease (CAD) [8] and heart failure [9, 10]. A recent, systematic review indicates that in particular poor physical-but less so mental-health status is a significant predictor for poor prognosis, independent of indicators of somatic disease severity and comorbidities [11]. However, only one study focused on patients treated with percutaneous coronary intervention (PCI), and the latter study was conducted prior to the introduction of drug-eluting stents in general clinical practice [11]. Given that drug-eluting stenting reduces the restenosis rate substantially [12], which in turn may lead to improved health status and quality of life, it is important to examine whether health status also predicts prognosis in the drug-eluting stent era.

Hence, in the current study, we examined whether poor health status, as measured with the brief and validated EQ-5D [12], predicts clinical events at follow-up in a consecutive series of patients treated with PCI with drugeluting stenting.

\section{Materials and methods}

Patients and design

In the period from 15 February 2005 to 14 February 2006, all consecutive patients treated with PCI due to a myocardial infarction (MI) or angina (unstable or stable) in the Erasmus Medical Center Rotterdam, The Netherlands, were asked to participate in the current study, if alive 1 month post-PCI. The paclitaxel-eluting stent was used as the default strategy for patients undergoing PCI in our institution during this period. We approached the municipal civil registries in the first month after the index PCI procedure to obtain survival status. If patients were still alive, they were approached by mail and asked to complete the EQ-5D, which is a brief, standardized and validated selfreport questionnaire that assesses health status as reported by the patient [13]. Assessment 1 month post-PCI (referred to as baseline in the remainder of the article) was in part chosen due to logistic reasons, but concerns have also been voiced that assessment of patient-centered outcomes, such as health status and depression, too close to an acute cardiac event may be more likely to reflect physical ill health rather than true symptomatology [14]. If patients did not return the questionnaire, they received a reminder via the mail together with a new questionnaire.

The medical ethics committee of the Erasmus Medical Center approved the study protocol. The study was carried out in accordance with the Declaration of Helsinki, and all patients provided written informed consent.

Materials

\section{Demographic and clinical variables}

Demographic variables included gender and age. Information on clinical variables (i.e., indication for PCI (MI versus stable/unstable angina), multi-vessel disease, previous MI, previous PCI, previous coronary artery bypass graft surgery (CABG), hypertension, hypercholesterolemia, and diabetes) and cardiac medication (i.e., aspirin, calcium antagonists, beta-blockers, ACE inhibitors, statins, diuretics, clopidogrel, and heparin) were retrieved from the patients' medical records. Smoking status was assessed by means of self-report.

\section{Health status}

The EQ-5D, a generic measure of perceived health status developed by the EuroQol Group, was used to assess general health status in the current study [13]. The EQ-5D consists of a visual analogue scale (VAS), with patients rating their health status on a scale from 0 (worst imaginable health status) to 100 (best imaginable health status), and a descriptive system comprising five questions assessing the following domains: Mobility, self-care, usual activities, pain/discomfort, and anxiety/depression. Each question can be scored as: having no problems (level 1), some problems (level 2), or severe problems (level 3). In addition, it is possible to calculate a utility score, a single summary index derived on the basis of the EQ-5D domains, with this information being useful in cost-utility analysis. However, given that we did not compare two treatment options and their associated costs, we did not use the utility score in the current study. In the present study, the VAS scale was dichotomized using the 25 th percentile (cut-off $\leq 60$ ) to indicate poor health status [8], while the EQ-5D levels were dichotomized into 'no problems' (i.e., level 1) versus 'problems' (i.e., levels 2 and 3) [15]. Others have also advocated the dichotomization of patient-centered outcomes, such as health status, in order to enhance 
clinical interpretability [16]. The EQ-5D is a brief and practical instrument, with satisfactory validity and reliability for various diseases, including CAD, and for the general population $[17,18]$.

\section{Clinical endpoint}

The clinical endpoint was defined as death (all-cause) or non-fatal MI at 1 year (median $=1.2$ years), with followup being complete for all patients. Survival status at 1 year was obtained from municipal civil registries. Reinfarction was diagnosed by recurrent symptoms and/or new electrocardiographic changes in association with increases in creatine kinase and creatine kinase myoglobin levels of $>3$ times the upper normal limit [19, 20]. A combined endpoint of death/non-fatal MI was used, due to the length of the follow-up period, but also since a combined endpoint is often used as a cardiovascular outcome measure. As the principal regional cardiac referral center, repeat procedures (percutaneous and surgical) are normally performed at our institution and recorded prospectively in our database. However, given that over $80 \%$ of the patients are referred from hospitals in the area, and in order to ensure that all MIs and repeat procedures were captured, patients were asked by means of a postal survey at 1 year if they had experienced an event during the follow-up period, with a response rate of $75-80 \%$. This information was verified against the medical records, and if necessary via general practitioners or referring cardiologists; 90-95\% of all patients with an event had responded to our postal survey.

\section{Statistical analyses}

Differences on nominal variables were compared with the chi-square test (Fisher's exact test when appropriate) and with Student's $t$-test for continuous variables. Unadjusted and adjusted Cox proportional hazard regression analyses were used to examine the impact of poor health status on prognosis. Separate univariable and multivariable Cox proportional hazard regression analyses were performed, entering each of the health status domains as the independent variable, and the clinical endpoint as the outcome (dependent variable). Multivariable analyses were conducted using a sequential modeling approach, entering demographic and clinical characteristics (i.e., gender, age, indication for PCI, multi-vessel disease, cardiac history (defined as previous MI, PCI, or CABG), comorbidities (defined as hypertension, hypercholesterolemia, or diabetes), smoking, and PCI or CABG during the follow-up period) in the first block and the health status domain in question in the second block, in order to determine whether the addition of health status added to the level of prediction of the model. Kaplan-Meier curves were generated to graphically present the time to death/MI for patients with poor versus good health status. The log-rank test was used to ascertain whether differences between groups were statistically significant. All tests were two-tailed $(P$-value $<.05)$; for Cox proportional hazard regression analyses, hazard ratios (HR) and their corresponding 95\% confidence intervals $(\mathrm{CI})$ are reported. All data were analyzed using SPSS 17.0 for Windows (SPSS Inc., Chicago, Illinois).

\section{Results}

Non-participants versus participants on baseline characteristics

A flowchart of the patient selection for the current study is presented in Fig. 1. Participants $(n=870)$ were more likely to be older (mean age $=62.7 \pm 11.5$ vs. $60.2 \pm 13.4$; $P=.006)$, to have hypercholesterolemia $(81.0 \%$ vs. $71.9 \% ; P=.001)$, and to be prescribed aspirin $(92.6 \% \mathrm{vs}$. $87.1 \% ; P=.005)$ and clopidogrel $(90.8 \%$ vs. $83.1 \%$; $P<.001)$ compared to non-participants $(n=302)$. No other statistically significant differences were found between participants and non-participants on demographic and clinical baseline characteristics.

\section{Baseline characteristics}

There were 53 events (deaths $=39$; MIs = 14) at followup. During the follow-up period, 51 (5.9\%) of patients underwent a revascularization procedure (i.e., PCI or CABG). Patient baseline characteristics for the total sample and stratified by death/MI at follow-up are presented in Table 1. Patients who experienced an event during followup were likely to be older (mean age $=67.8 \pm 9.8$ vs.

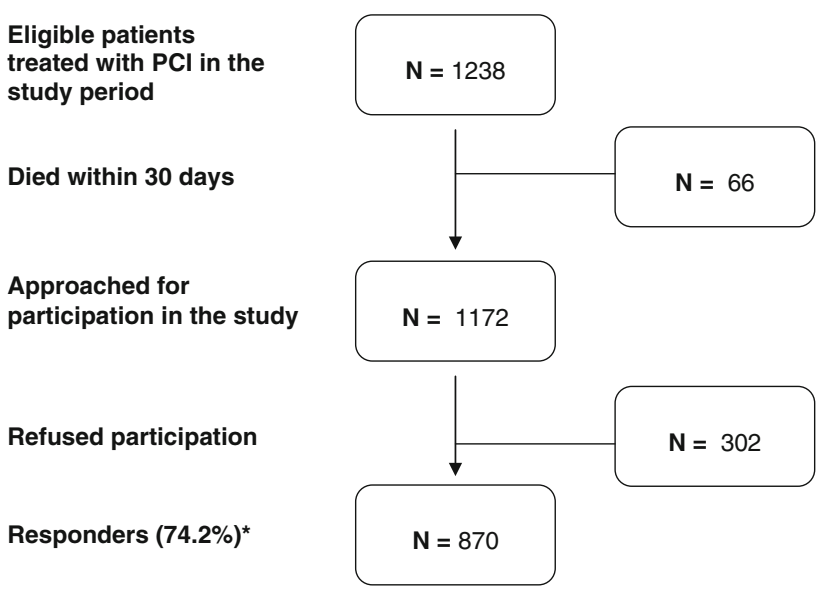

Fig. 1 Flowchart of patient selection for the current study. * Due to missings on some of the EQ-5D dimensions, the number of patients included in the analyses ranged from 870 to 814 patients, as follows: Mobility $(n=870)$, self-care $(n=852)$, usual activities $(n=851)$, pain $(n=846)$, anxiety/depression $(n=852)$, and VAS $(n=818)$ 
$62.3 \pm 11.5 ; P=.001)$ and less likely to be prescribed beta-blockers $(41.5 \%$ vs. $62.9 \% ; P=.003)$ and statins (60.4\% vs. $73.8 \% ; P=.048)$ compared to patients without an event. A trend was found for diabetes, with patients with diabetes more likely to experience an event compared to patients without diabetes $(26.4 \%$ vs. $16.4 \% ; P=.09)$.

Impact of health status on death/MI at follow-up (unadjusted)

The Kaplan-Meier curves in Fig. 2 show the impact of the EQ-5D health status domains on death/MI at follow-up, with the associated incidence of events, hazard ratios, 95\% CI presented in Table 2. Poor mobility, poor self-care, and the inability to perform usual activities were associated with an increased risk of 1-year death/MI, with HRs ranging from 1.78 to 3.90. Poor self-reported health status on the EQ-5D VAS was also a predictor of death/MI (HR: 2.76; 95\% CI: 1.57-4.83; $P<.001)$. The EQ-5D dimensions pain/discomfort and anxiety/depression were not associated with prognosis.

Impact of health status on death/MI at follow-up (adjusted)

In order to ascertain whether the impact of health status on prognosis could be attributed to disease severity and other demographic and clinical confounders, multivariable Cox proportional hazard regression models were run separately for the EQ-5D health status domains using a sequential modeling approach, entering demographic and clinical characteristics in the first block and the health status domain in question in the second block. In multivariable analyses, poor mobility (HR: 2.23; 95\% CI: 1.25-3.97; $P=.006$ ), poor self-care (HR: 3.09 ; $95 \% \mathrm{CI}: 1.54-6.20, P=.002$ ), and poor self-reported health status as measured by the EQ-5D VAS (HR: 2.94; 95\% CI: 1.65-5.25; $P<.001$ ) remained independent predictors of death/MI at follow-up, whereas the inability to perform usual activities was no longer associated with adverse clinical outcome (Table 3 ). The addition of health status to a model comprised of demographic and clinical characteristics (i.e., gender, age, indication for PCI, multi-vessel disease, cardiac history (defined as previous MI, $\mathrm{PCI}$, or $\mathrm{CABG}$ ), comorbidities (defined as hypertension, hypercholesterolemia, or diabetes), smoking, and PCI or CABG during the follow-up period) added to the level of prediction of the model as indicated by a significant change in the chi-square value compared to the previous block, with respect to poor mobility $\left(\chi^{2}=7.441 ; d f=1 ; P=.006\right)$, poor self-care $\left(\chi^{2}=8.502 ; d f=1 ; P=.004\right)$, and poor self-reported health status as measured by the EQ-5D VAS $\left(\chi^{2}=13.093 ; d f=1 ; P<.001\right)$ but not the other domains $(p \mathrm{~s}>0.05)$.
Table 1 Baseline

characteristics for the total sample and stratified by death/ MI at follow-up

Results are presented as $n(\%)$, unless otherwise indicated

$M I$ Myocardial infarction, $P C I$ percutaneous coronary intervention, $C A B G$ coronary artery bypass graft surgery

a $140 / 90 \mathrm{mmHg}$ or being treated for hypertension

b $\geq 240 \mathrm{mg} / \mathrm{dL}$ or being treated for hypercholesterolemia

${ }^{c}$ Being treated for diabetes

d Based on the patient's selfreport

\begin{tabular}{|c|c|c|c|c|}
\hline & Total $(n=870)$ & $\begin{array}{l}\text { Event during } \\
\text { follow-up }(n=53)\end{array}$ & $\begin{array}{l}\text { No event during } \\
\text { follow-up }(n=817)\end{array}$ & $P$ \\
\hline \multicolumn{5}{|l|}{ Demographics } \\
\hline Male gender & $628(72.2)$ & $38(71.7)$ & $590(72.2)$ & 1.00 \\
\hline Age, mean $\pm \mathrm{SD}$ & $62.6 \pm 11.5$ & $67.8 \pm 9.8$ & $62.3 \pm 11.5$ & .001 \\
\hline \multicolumn{5}{|l|}{ Clinical } \\
\hline MI as indication for PCI & $290(33.3)$ & $23(43.4)$ & $267(32.7)$ & .15 \\
\hline Multi-vessel disease & $416(47.8)$ & $30(56.6)$ & $386(47.2)$ & .24 \\
\hline Previous MI & $226(26.0)$ & $13(24.5)$ & $213(26.1)$ & .93 \\
\hline Previous PCI & $243(27.9)$ & $11(20.8)$ & $232(28.4)$ & .30 \\
\hline Previous CABG & $74(8.5)$ & $3(5.7)$ & $71(8.7)$ & .61 \\
\hline Hypertension $^{\mathrm{a}}$ & $379(43.6)$ & $23(43.4)$ & $356(43.6)$ & 1.00 \\
\hline Hypercholesterolemia $^{\mathrm{b}}$ & $705(81.0)$ & $38(71.7)$ & $667(81.6)$ & .11 \\
\hline Diabetes $^{c}$ & $148(17.0)$ & $14(26.4)$ & $134(16.4)$ & .09 \\
\hline Smoking ${ }^{\mathrm{d}}$ & $216(24.8)$ & $18(34.0)$ & $198(24.2)$ & .15 \\
\hline \multicolumn{5}{|l|}{ Medication } \\
\hline Aspirin & $806(92.6)$ & $49(92.5)$ & 757 (92.7) & 1.00 \\
\hline Calcium antagonists & $24(2.8)$ & $1(1.9)$ & $23(2.8)$ & 1.00 \\
\hline Beta-blockers & $536(61.6)$ & $22(41.5)$ & $514(62.9)$ & .003 \\
\hline ACE inhibitors & $330(37.9)$ & $17(32.1)$ & $313(38.3)$ & .45 \\
\hline Statins & $635(73.0)$ & $32(60.4)$ & $603(73.8)$ & .048 \\
\hline Diuretics & $87(10.0)$ & $5(9.4)$ & $82(10.0)$ & 1.00 \\
\hline Clopidogrel & $790(90.8)$ & $47(88.7)$ & 743 (90.9) & .76 \\
\hline Heparin & 135 (15.5) & 10 (18.9) & 125 & .62 \\
\hline
\end{tabular}


Fig. 2 Incidence of death/MI at follow-up stratified by poor health status. The number of patients included in the analyses varies between 845 and 870 across the health status domains, as some patients had not completed all items
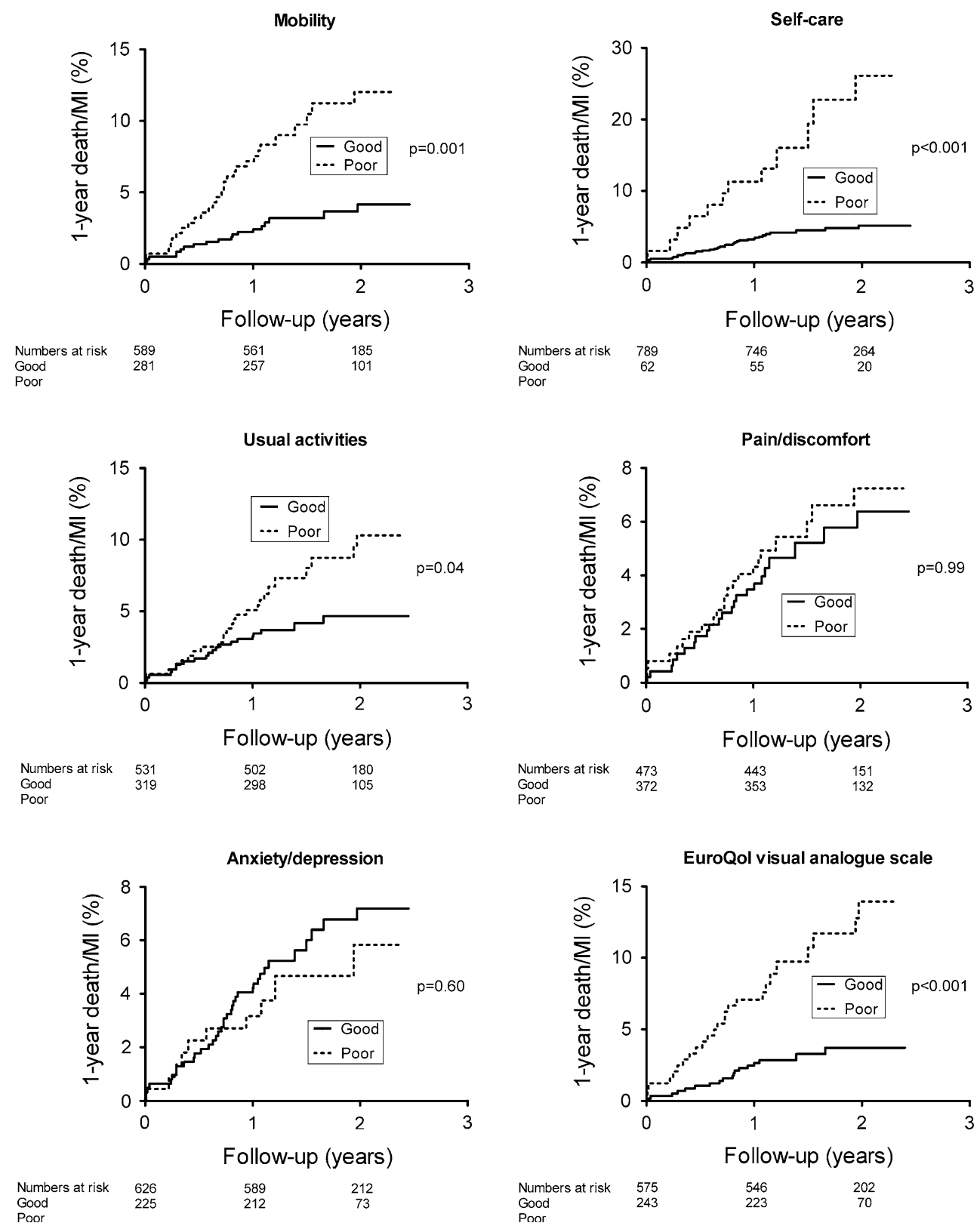

\section{Discussion}

In the current study, health status as reported by the patient was shown to predict death or MI at follow-up in PCI patients treated with drug-eluting stenting and to add to the level of prediction of a model comprised of demographic and clinical characteristics. The impact of health status on death/MI was independent of disease severity and other demographic and clinical characteristics known to predict major adverse clinical events. The risk incurred by poor mobility, poor selfcare, and poor self-rated health status as measured with the EQ-5D VAS was more than twofold, whereas the EQ-5D dimensions usual activities, pain/discomfort, and anxiety/ depression were not related to clinical outcome.
Similar to the Euro Heart Survey on coronary revascularization conducted prior to the introduction of drugeluting stenting [8], we found that of the five descriptive domains of the EQ-5D poor self-care was the most powerful predictor of mortality and non-fatal MI, with the adjusted risk being almost threefold. Self-care, comprising an important part of the management of chronic conditions, such as CAD, diabetes, and heart failure, refers to a set of daily behaviors, including the monitoring of symptoms and consulting a physician when necessary, performed by the patient to manage his or her condition and to promote health [21,22]. Self-care and its impact on health outcomes have received most attention in patients with heart failure $[21,23]$. This may be attributed to the chronicity of the 
Table 2 Impact of health status on death/MI (unadjusted)
The number of patients included in the analyses differs across the health status domains, as some patients had not completed all items

$E Q$-VAS EQ visual analogue scale

\begin{tabular}{|c|c|c|c|c|c|}
\hline & $\begin{array}{l}\text { Event during } \\
\text { follow-up } n(\%)\end{array}$ & $\begin{array}{l}\text { No event during } \\
\text { follow-up } n(\%)\end{array}$ & HR & {$[95 \% \mathrm{CI}]$} & $P$ \\
\hline Mobility & & & 2.50 & {$[1.45-4.29]$} & .001 \\
\hline No problems & $24(4.1)$ & $565(95.9)$ & & & \\
\hline Problems & $29(10.3)$ & $252(89.7)$ & & & \\
\hline Self-care & & & 3.90 & {$[2.05-7.44]$} & $<.001$ \\
\hline No problems & $40(5.1)$ & $749(94.9)$ & & & \\
\hline Problems & $12(19.4)$ & $50(80.6)$ & & & \\
\hline Usual activities & & & 1.78 & {$[1.03-3.06]$} & .04 \\
\hline No problems & $25(4.7)$ & $506(95.3)$ & & & \\
\hline Problems & $27(8.5)$ & $292(91.5)$ & & & \\
\hline Pain/discomfort & & & 1.00 & [0.58-1.74] & .99 \\
\hline No problems & $28(5.9)$ & $445(94.1)$ & & & \\
\hline Problems & $23(6.2)$ & $349(93.8)$ & & & \\
\hline Anxiety/depression & & & 0.84 & {$[0.44-1.61]$} & .60 \\
\hline No problems & $40(6.4)$ & $586(93.6)$ & & & \\
\hline Problems & $12(5.3)$ & $213(94.7)$ & & & \\
\hline EQ-VAS & & & 2.76 & {$[1.57-4.83]$} & $<.001$ \\
\hline No problems & $23(4.0)$ & $552(96.0)$ & & & \\
\hline Problems & $26(10.7)$ & $217(89.3)$ & & & \\
\hline
\end{tabular}

condition and its associated functional impairments and poor prognosis, with poor self-care more likely to have an immediate impact on both functional status and quality of life and prognosis in heart failure compared to more benign conditions such as elective PCI due to stable CAD. However, the current results indicate that it is important also in PCI patients to tend to the issue of self-care.

In the current study, poor mobility was also an important and independent predictor of adverse clinical events at follow-up. This finding is consistent with previous studies showing that the extent of disability as perceived by the patient predicts poor prognosis and quality of life both in patients with CAD and heart failure, adjusting statistically for indicators of disease severity, such as left ventricular dysfunction and NYHA functional class [8, 11, 24-26]. This was also confirmed in a recent systematic review on the impact of patient-rated health status on mortality and readmission in patients with CAD and heart failure [11].

The recent results of the Clinical Outcomes Utilizing Revascularization and Aggressive Drug Evaluation (COURAGE) trial, randomizing patients with stable CAD to either PCI with optimal medical therapy or optimal medical therapy alone, testify to the utility of incorporating a measure of health status in research and clinical practice $[2,8]$. Patients enrolled in the COURAGE trial with more frequent anginal complaints, as assessed with the Seattle Angina Questionnaire, derived the most benefit from PCI in combination with optimal medical therapy. Patients with more severe anginal complaints would likely not be identified in clinical practice based on the clinician's judgment alone, in particular since physicians seem to underestimate the disability of patients [6,7]. Taken together with the results of the current study, this indicates that assessment of patients' health status as part of routine clinical care may be helpful in clinical decision-making and risk stratification and be instrumental in identifying high-risk patients who may need more aggressive medical treatment and who might also benefit from adjunctive intervention to increase adherence with lifestyle changes, such as exercising and smoking cessation. Assessment of health status as part of routine clinical practice would thus enable treatment recommendations to be tailored to individual patients. The clinical utility of incorporating health status measures in the clinical care and management of cardiac patients is further elaborated upon in a seminal paper by Spertus [3] and in a recent review of the impact of poor health status on clinical outcomes in CAD and heart failure by Mommersteeg and colleagues [11].

An advantage of using the EQ-5D as a measure of health status in clinical practice is that it is brief and takes up little time for patients to complete compared to other more lengthy measures, such as the 36-item Short Form Health Survey (SF-36), which is often used in CAD patients. However, despite the prognostic value of the EQ-5D as shown here and in another study [8], the instrument may be less suitable to use as an outcome measure to tap treatmentrelated changes, as it is likely to be less sensitive compared to a disease-specific measure [11].

The results of the current study should be interpreted with some caution due to the following limitations. First, a 


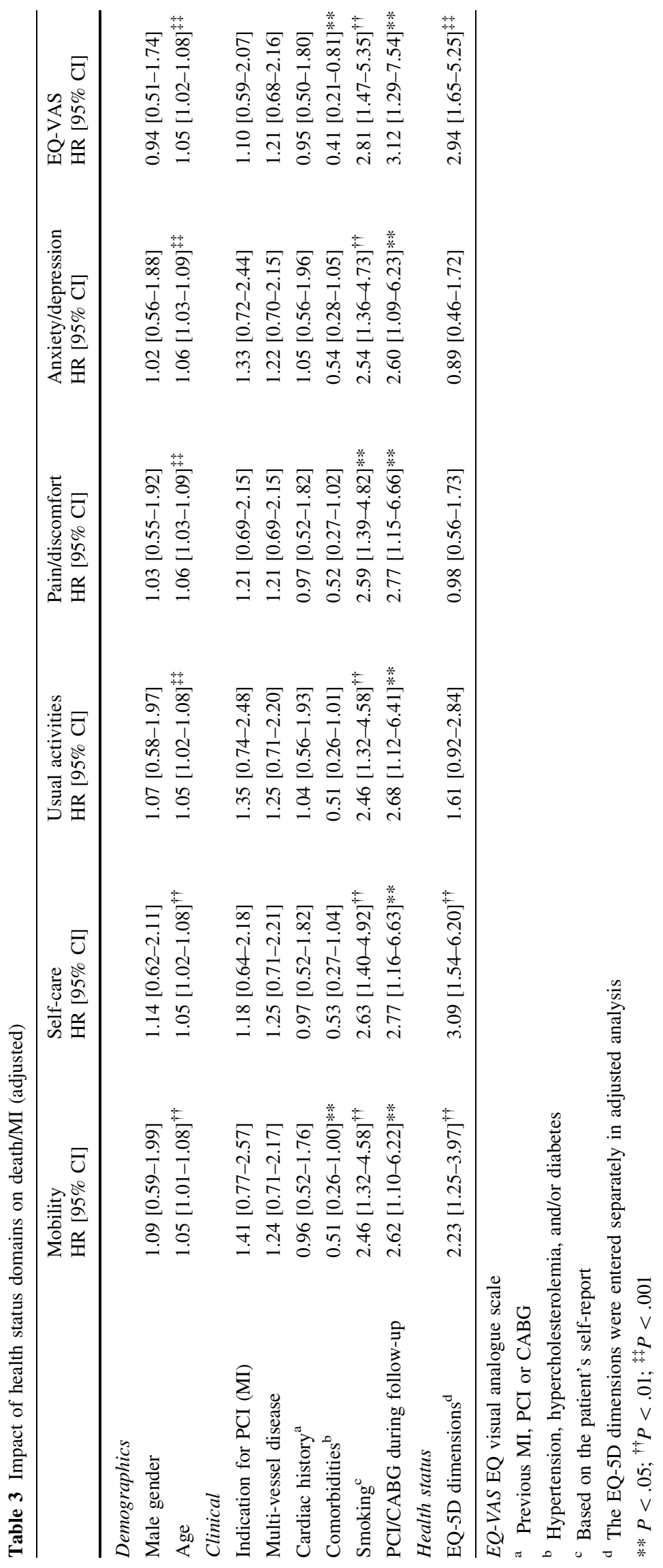


selection bias may have occurred, since patients who died within the first 1 month post-PCI did not have the opportunity to participate in the study, in turn limiting the generalizability of the findings. Second, we used the EQ-5D, which is a generic rather than a disease-specific measure of health status, since standardized and validated diseasespecific measures, such as the Seattle Angina Questionnaire (19 items) and the MacNew Quality of Life Questionnaire (27 items), tend to be longer. However, a diseasespecific measure is likely to be more sensitive to tap symptoms that are important to patients. In addition, the EQ-5D contains only one question tapping into the five descriptive dimensions of mobility, self-care, usual activities, pain/discomfort, and anxiety/depression, which provides little room for variability in scores. Nevertheless, the EQ-5D health status domains poor mobility and poor selfcare, and the EQ-5D VAS predicted adverse clinical events despite adjustment for standard, biomedical risk factors. Third, we had no information on renal failure, angina severity, NYHA functional class, heart failure, left ventricular ejection fraction, number of hospitalizations during follow-up, participation in cardiac rehabilitation, socioeconomic status, and the use of psychotropic medication, which could serve as potential confounders. However, we did adjust for multi-vessel disease, as an indicator of somatic disease severity. Fourth, the multivariable models were not formally validated by means of the bootstrapping method nor in a different, independent population, but the results were consistent with the findings of Lenzen and colleagues [8], who also examined the predictive validity of the EQ-5D in patients treated with coronary revascularization, although prior to the drug-eluting stent era.

In conclusion, several health status dimensions as measured with the brief and validated EQ-5D predicted death or non-fatal MI at follow-up in PCI patients treated with drug-eluting stenting. The risk associated with poor health status was more than twofold and was independent of disease severity and other demographic and clinical characteristics. To our knowledge, this is only the second study to have examined the predictive validity of the EQ$5 \mathrm{D}$ as a measure of health status in patients with CAD and heart failure [11], and the first study to show that poor patient-rated health status predicts adverse clinical events in PCI patients despite optimal treatment with drug-eluting stenting. It may be timely to adopt standard assessment of health status in clinical practice, given evidence from this and other studies that patient-rated health status has unique prognostic value.

Conflicts of interest There are no conflicts of interest nor any financial support to declare.

Open Access This article is distributed under the terms of the Creative Commons Attribution Noncommercial License which permits any noncommercial use, distribution, and reproduction in any medium, provided the original author(s) and source are credited.

\section{References}

1. Krumholz, H. M., Peterson, E. D., Ayanian, J. Z., Chin, M. H., DeBusk, R. F., Goldman, L., et al. (2005). Report of the National Heart, Lung, and Blood Institute working group on outcomes research in cardiovascular disease. Circulation, 111(23), 31583166.

2. Weintraub, W. S., Spertus, J. A., Kolm, P., Maron, D. J., Zhang, Z., Jurkovitz, C., et al. (2008). Effect of PCI on quality of life in patients with stable coronary disease. New England Journal of Medicine, 359(7), 677-687.

3. Spertus, J. A. (2008). Evolving applications for patient-centered health status measures. Circulation, 118(20), 2103-2110.

4. Raphael, C., Briscoe, C., Davies, J., Ian Whinnett, Z., Manisty, C., Sutton, R., et al. (2007). Limitations of the New York Heart Association functional classification system and self-reported walking distances in chronic heart failure. Heart, 93(4), 476-482.

5. Bennett, J. A., Riegel, B., Bittner, V., \& Nichols, J. (2002). Validity and reliability of the NYHA classes for measuring research outcomes in patients with cardiac disease. Heart and Lung, 31(4), 262-270.

6. Calkins, D. R., Rubenstein, L. V., Cleary, P. D., Davies, A. R., Jette, A. M., Fink, A., et al. (1991). Failure of physicians to recognize functional disability in ambulatory patients. Annals of Internal Medicine, 114(6), 451-454.

7. Lieberman, J. R., Dorey, F., Shekelle, P., Schumacher, L., Thomas, B. J., Kilgus, D. J., et al. (1996). Differences between patients' and physicians' evaluations of outcome after total hip arthroplasty. Journal of Bone and Joint Surgery, 78(6), 835-838.

8. Lenzen, M. J., Scholte op Reimer, W. J., Pedersen, S. S., Boersma, E., Maier, W., Widimsky, P., et al. (2007). The additional value of patient-reported health status in predicting 1-year mortality after invasive coronary procedures: A report from the Euro Heart Survey on Coronary Revascularisation. Heart, 93(3), 339-344.

9. Soto, G. E., Jones, P., Weintraub, W. S., Krumholz, H. M., \& Spertus, J. A. (2004). Prognostic value of health status in patients with heart failure after acute myocardial infarction. Circulation, 110(5), 546-551.

10. Rumsfeld, J. S., MaWhinney, S., McCarthy, M., Jr., Shroyer, A. L., VillaNueva, C. B., O’Brien, M., et al. (1999). Health-related quality of life as a predictor of mortality following coronary artery bypass graft surgery. Participants of the Department of Veterans Affairs Cooperative Study Group on Processes, Structures, and Outcomes of Care in Cardiac Surgery. The Journal of the American Medical Association, 281(14), 1298-1303.

11. Mommersteeg, P. M. C., Denollet, J., Spertus, J. A., \& Pedersen, S. S. (2009). Health status as a risk factor in cardiovascular disease: A systematic review of current evidence. American Heart Journal, 157(2), 208-218.

12. Greenhalgh J, Hockenhull J, Rao N, Dundar Y, Dickson RC, Bagust A. (2010). Drug-eluting stents versus bare metal stents for angina or acute coronary syndromes. Cochrane Database of Systematic Reviews 2010, 5, Art. No.: CD004587. doi: 10.1002/ 14651858.CD004587.pub2.

13. EuroQol-group. (1990). Euroqol-a new facility for the measurement of health-related quality of life. The EuroQol Group. Health Policy, 16(3), 199-208.

14. Nicholson, A., Kuper, H., \& Hemingway, H. (2006). Depression as an aetiologic and prognostic factor in coronary heart disease: a 
meta-analysis of 6362 events among 146538 participants in 54 observational studies. European Heart Journal, 27(23), 2763-2774.

15. Kind, P., Dolan, P., Gudex, C., \& Williams, A. (1998). Variations in population health status: results from a United Kingdom national questionnaire survey. British Medical Journal, 316(7133), 736-741.

16. Rumsfeld, J. S., Magid, D. J., Plomondon, M. E., Sales, A. E., Grunwald, G. K., Every, N. R., et al. (2003). History of depression, angina, and quality of life after acute coronary syndromes. American Heart Journal, 145(3), 493-499.

17. Brooks, R. (1996). EuroQol: The current state of play. Health Policy, 37, 53-72.

18. Schweikert, B., Hahmann, H., \& Leidl, R. (2006). Validation of the EuroQol questionnaire in cardiac rehabilitation. Heart, 92(1), 62-67.

19. Daemen, J., Tanimoto, S., Garcia-Garcia, H. M., Kukreja, N., van de Sande, M., Sianos, G., et al. (2007). Comparison of three-year clinical outcome of sirolimus- and paclitaxel-eluting stents versus bare metal stents in patients with ST-segment elevation myocardial infarction (from the RESEARCH and T-SEARCH Registries). American Journal of Cardiology, 99(8), 1027-1032.

20. Smith, S. C., Jr., Feldman, T. E., Hirshfeld, J. W., Jr., Jacobs, A. K., Kern, M. J., King, S. B., 3rd, et al. (2006). ACC/AHA/SCAI 2005 Guideline Update for Percutaneous Coronary InterventionSummary Article: A Report of the American College of Cardiology/American Heart Association Task Force on Practice Guidelines (ACC/AHA/SCAI Writing Committee to Update the
2001 Guidelines for Percutaneous Coronary Intervention). Journal of the American College of Cardiology, 47(1), 216-235.

21. Jovicic, A., Holroyd-Leduc, J. M., \& Straus, S. E. (2006). Effects of self-management intervention on health outcomes of patients with heart failure: a systematic review of randomized controlled trials. BMC Cardiovascular Disorders, 6, 43.

22. Barlow, J., Wright, C., Sheasby, J., Turner, A., \& Hainsworth, J. (2002). Self-management approaches for people with chronic conditions: a review. Patient Education and Counseling, 48(2), $177-187$.

23. Grady, K. L. (2008). Self-care and quality of life outcomes in heart failure patients. Journal Cardiovascular Nursing, 23(2), 285-292.

24. Yuval, R., Halon, D. A., \& Lewis, B. S. (2007). Perceived disability and lifestyle modification following hospitalization for non-ST elevation versus ST elevation acute coronary syndromes: the patients' point of view. European Journal of Cardiovascular Nursing, 6(4), 287-292.

25. Smith, O. R., Pedersen, S. S., Van Domburg, R. T., \& Denollet, J. (2008). Symptoms of fatigue and depression in ischemic heart disease are driven by personality characteristics rather than disease stage: a comparison of CAD and CHF patients. European Journal of Cardiovascular Prevention and Rehabilitation, 15(5), 583-588.

26. van der Vlugt, M. J., van Domburg, R. T., Pedersen, S. S., Veerhoek, R. J., Leenders, I. M., Pop, G. A., et al. (2005). Feelings of being disabled as a risk factor for mortality up to 8 years after acute myocardial infarction. Journal of Psychosomatic Research, 59(4), 247-253. 